Ryo Kitahara ${ }^{1}$, Kazuyuki Akasaka ${ }^{2},\left({ }^{1}\right.$ College of Pharmaceutical Sciences, Ritsumeikan University: ${ }^{2}$ High Pressure Protein Research Center, Kinki University)

The structure of a protein in solution takes not only basic folded state but also higher-energy states at physiological condition. We characterized lowpopulated locally disordered structures of proteins by using high pressure NMR spectroscopy. Outer surface protein A (OspA) from Borrelia burgdorferi is involved in the transmission of Lyme disease from the host tick to the mammals. We found that the folded structure undergoes a large scale, but rare transition into a locally disordered structure in which about C-terminal two thirds of the protein involving the receptor binding region is disordered with the rest of the molecule largely intact. We speculate that the disordering of the receptor binding region may play an important role for the receptor recognition, as it is like a putative fly-casting model of molecular recognition for the natively unfolded proteins/domains. We also found locally disordered structures conserved in the functionally related homologues (ubiquitin and ubiquitin-like proteins NEDD8 and SUMO-2), indicating a conserved structural design for their common functional strategy. A notable difference is a thermodynamic design. For instance, NEDD8 and SUMO-2 have markedly higher populations of locally and totally unfolded structures than ubiquitin, resulting in markedly quicker enzymatic degradation than ubiquitin. These results suggest strongly that populations and structures of locally disordered states characterize functions such as molecular recognition, reactivity and degradability in cell physiology.

2SE1040 Volumetric Properties of Amyloid Fibrillation Starting from Unfolded High-Energy Protein Structures

Hideki Tachibana ${ }^{1,3}$, Ryohei Kono ${ }^{2,3}$, Kazuyuki Akasaka ${ }^{3},\left({ }^{1}\right.$ Dept Biotech Sci, Sch Biol-Oriented Sci Tech, Kinki Univ: ${ }^{2}$ Sec Dept Int Med, Wakayama Med Univ: ${ }^{3}$ High Pressure Prot Res Center, Inst Adv Tech, Kinki Univ)

Formation of amyloid fibrils has been shown to involve protein unfolded state. One example is lysozyme, in which amyloidogenic variants show decreased stability and decreased cooperativity of unfolding while WT protein fibrillates only under highly denaturing conditions. We have shown that an intrinsically unfolded disulfide-deficient variant of hen lysozyme, termed OSS, spontaneously forms amyloid-like fibrils. As "volume theorem" states, structured OSS fibrils facilely dissociate under high hydrostatic pressure into unstructured monomeric units with a decrease in partial molar volume of about hundred $\mathrm{mL}$. A negative activation volume and a negative activation compressibility were obtained from kinetic analyses of the pressure-dissociation, which indicates that the fibrillar state is rich in voids and highly compressible, while it is partially hydrated and becomes less compressible in the transition state. The unstructured monomeric state of OSS assumes the lowest volume with full hydration. Unlike the nearly-fully unfolded OSS variant, lysozyme variants that have intermediate numbers of native disulfide bonds represent a series of proteins with different extent of partial unfolding and/or global destabilization. Seeded-fibrillation of these SS-variants under the conditions where spontaneous fibrillation is difficult to occur showed that some native disulfide bonds are positively involved in amyloid fibrillation, ie, nonnative intermolecular folding process.

\section{SE1100 高エネルギー構造を介するプリオン蛋白質の異常型変換機構} High-Energy Conformers of Prion Proteins.: A Key to the Abnormal Fibril Formation

Ryuichiro Atarashi, (Department of Molecular Microbiology and Immunology. Nagasaki University Graduate School of Biomedical Sciences)

The main molecular event of prion diseases is the conversion of the normal protease-sensitive form of prion protein (PrPC or PrP-sen) into pathological protease-resistant prion protein (PrPSc or PrP-res). According to the proteinonly hypothesis, the continuous conversion of PrPC to PrPSc in infected hosts is the mechanism of prion propagation. To further understand mechanistic details of the conversion, we developed an in vitro PrPSc amplification assay designated quaking-induced conversion (QUIC), which involves intermittent, automated shaking of the substrate, soluble recombinant $\operatorname{PrP}$ (rPrP-sen). This conversion process appears to share a common molecular basis similar to amyloid fibril formation. In the presentation, we focus on the role of high-energy conformers of rPrP-sen in the QUIC reaction.

\section{SE1355 錐体・桿体視細胞の応答様式を決める分子メカニズム}

Molecular mechanisms determining photoresponse characteristics in rod and cone photoreceptor cells.

Shuji Tachibanaki, Satoru Kawamura, (Osaka University)

In the vertebrate retina, there are two types of visual photoreceptor cells, called rods and cones. It is known that the phototransduction mechanisms in rods and cones are homologous. However, it is also well known that the photoresponse characteristics are different between rods and cones. For example, in cones, the photosensitivity is lower and the duration of a photoresponse is shorter than in rods. It has been speculated that these differences between rods and cones are caused by the different efficiencies of the enzymatic reactions in homologous phototransduction mechanisms. However, direct evidence of this working hypothesis had not been obtained due to a difficulty in purification of cone cells. Fortunately, several years ago, we succeeded in developing a method to isolate and purify rods and cones from a carp retina in a quantity large enough to perform biochemical analysis. By using purified cells, we found that the efficiency of G-protein $(\mathrm{Gt})$ activation by a photoactivated visual pigment is lower in cones than in rods. This lower efficiency for Gt activation should explains lower photosensitivity in cones. We also found that inactivation of activated Gt is much faster in cones than in rods. This fast inactivation should result in quick termination of a photoresponse in cones. It was also found that RGS9 is more abundant so that Gt is more effectively inactivated in cones than in rods. Based on these findings, molecular bases of the differences in the photoreceptor characteristics between rods and cones will be discussed.

\section{SE1415 視細胞円板膜上でのロドプシンとトランスデューシンの 1 分子 イメージング}

Single molecule imaging of rhodopsin and transducin in native disk membrane of rod photoreceptor

Keiji Seno ${ }^{1}$, Fumio Hayashi ${ }^{2}$, $\left({ }^{1}\right.$ Hamamatsu University School of Medicine: ${ }^{2}$ Kobe University $)$

Diffusion coefficients of rhodopsin and transducin in disk membranes are essential parameters determining amplification gain and temporal resolution of phototransduction in vertebrate rod photoreceptors. We examined their diffusivities by single molecule imaging technique on a TIRF microscope, and found that rhodopsin and transducin reduces their diffusivities when they form light-dependent complex, which is known to be extensively raftophilic. Since an artificially dimerized rhodopsin shows similar high raftophilicity and low diffusivity in the disk membrane, we expect that the binding of transducin to light-bleached rhodopsin stabilizes the dimer of rhodopsin. The stoichiometric ratio of rhodopsin and transducin in their light-induced complex was examined and found to be $2: 1$. Thus, it was suggested that rhodopsin and transducin form highly raftophilic $2: 1$ complex. However, in native GTP-rich condition, the average lifetime of this complex would be expected to be less than $10 \mathrm{~ms}$. Therefore, the photon adsorption would cause very transient and small inhomogeneity to the disk membrane. Physiological meaning of the formation of such short-lived nanodomain around the complex has remained to be clarified. Our observation on light- and GTP-dependent diffusivity of S-modulin, a myristoylated $\mathrm{Ca} 2+-$ dependent inhibitor of rhodopsin kinase, suggests the participation of light-induced nanodomains in the recruitment of $\mathrm{S}$-modulin to the vicinity of light-bleached rhodopsin.

\section{SE1440 脊椎動物ロドプシンを用いた GPCR の活性状態形成・G蛋白 質活性化の制御メカニズム}

Molecular mechanism regulating active state formation and $G$ protein activation of a prototypical GPCR, vertebrate rhodopsin

Takahiro Yamashita, (Department of Biophysics, Graduate School of Science, Kyoto University)

Vertebrate rhodopsin is the photoreceptor protein in the retina and one of the well-studied G protein-coupled receptors (GPCRs). It consists of the protein moiety, opsin, and the choromophore, 11-cis retinal. Photoisomerization of 11-cis to all-trans form within the transmembrane domains leads to the formation of the active state, metarhodopsin II (MII). This is a unique mechanism compared with other GPCRs bound to diffusible ligands. However, recent studies have shown that vertebrate rhodopsin and other GPCRs can share common architectural features in the resting and active states. Therefore the studies of vertebrate rhodopsin provide valuable information about the activation process of G protein by GPCR; the active state formation of GPCR, the interaction between GPCR and $G$ protein and the nucleotide exchange in G protein.

In this study, time-resolved spectroscopy and biochemical techniques have been applied to a series of the mutants of rhodopsin and $G$ protein. The analysis about the $\mathrm{pH}$-dependent alteration of the transition from the precursor of MII to MII has revealed important intramolecular interactions to connect the retinal binding site and the protein surface in MII formation. In addition, the analysis of the interface region in $G$ protein bound to rhodopsin has given novel insight into the molecular basis of the interaction between MII and G protein and the following GDP/GTP exchange in G protein. Based on these studies, I will discuss the activation process of a prototypical GPCR, vertebrate rhodopsin. 